Published in final edited form as:

Neurosurg Q. 2009 December 1; 19(4): 302-307. doi:10.1097/WNQ.0b013e3181bd5f8c.

\title{
Surgical Management of Cervical Spondylotic Myelopathy
}

\author{
Wesley Hsu, M.D., Michael J. Dorsi, M.D., and Timothy F. Witham, M.D. \\ Department of Neurosurgery, Johns Hopkins Medical Institutions, Baltimore, Maryland, USA
}

\begin{abstract}
Cervical spondylosis is a common degenerative condition that is a significant cause of morbidity. This review discusses the pathophysiology and natural history of cervical spondylotic myelopathy and focuses on the current literature evaluating the clinical management of these patients.
\end{abstract}

\section{Introduction}

Cervical spondylosis (CS) is a degenerative condition that is the most common nontraumatic cause of myelopathy in the cervical spine. $1^{-} 4$ This review will briefly discuss the pathophysiology and natural history of cervical spondylotic myelopathy (CSM) and focus on the current literature evaluating the clinical management of patients with CSM.

\section{Pathophysiology}

Multiple factors play a critical role in the development of CS and subsequent CSM. The cascade of spondylotic changes is likely to begin first with cervical disc degeneration. With aging, desiccation and fragmentation of the disc leads to disc collapse. Such changes are believed to cause mechanical stress on the endplates, which initiates osteophyte formation along the endplates. 5 These osteophytes serve to increase the load-bearing surface of the endplates to compensate for spine hypermobility secondary to the loss of disc material. ${ }^{6}$ Compensatory bone growth in the form of uncinate process hypertrophy may also occur. Ossification of the posterior longitudinal ligament (OPLL), most commonly seen in the Asian population, can also lead to CSM. Risk factors for CS include smoking, ${ }^{7}$ occupational trauma, 8 and Down syndrome. 9 Some patients may have a genetic predisposition to CS, although specific genes have not been identified. 10

CSM is a result of static and dynamic mechanical factors that cause repeated injury to the spinal cord. ${ }^{1}$ Static mechanical factors refer to pathology that contributes to narrowing of the spinal canal. For example, osteophyte formation decreases the diameter of the spinal canal and may compress the spinal cord directly. Hypertrophy of the ligamentum flavum, OPLL and subluxation or kyphosis of the cervical spine may also serve to narrow the spinal canal. The impact of these factors is exacerbated in patients with congenital cervical stenosis. ${ }^{11}$ Dynamic mechanical factors refer to the motion of the cervical spine during flexion or extension that contribute to spinal cord injury that may already be in progress secondary to the aforementioned static mechanical factors. Flexion of the cervical spine leads to compression of the spinal cord against osteophytic bars. Extension of the cervical spine leads to compression of the spinal cord against the buckled, hypertrophied ligamentum flavum. The combination of static and dynamic mechanical factors likely causes CSM as a result of both direct trauma as well as

Corresponding Author: Wesley Hsu, M.D., Department of Neurosurgery, The Johns Hopkins University School of Medicine, Meyer Bldg. 8-161, 600 N. Wolfe St., Baltimore, MD, 21287, weshsu@jhmi.edu, Telephone: 410-292-6713, Fax: 410-502-5768. 
spinal cord ischemia. It is believed that impaired blood flow through the spinal cord microcirculation plays a role in CSM. ${ }^{12}$

\section{Natural History of CSM}

Despite significant scholarly interest in CSM, the natural history of untreated CSM is not entirely clear. The classic study by Lees and Turner suggested that most patients experience an initial stage of deterioration. This was usually followed by clinical stability for several years, particularly for patients whose initial deterioration resulted in only mild symptoms. ${ }^{13}$ Nurick later confirmed this pattern of clinical outcomes. ${ }^{14}$ However, both studies noted that patients who were older or had significant progressive disability fared much worse than other patients. Other studies illustrate that CSM may progress at a variable rate and unpredictable time course. ${ }^{15-17}$ Furthermore, patients with stable clinical symptoms may later experience further decline. 17,18

It is argued that patients with CSM do not fare well with medical management, and patients who demonstrate minor myelopathic symptoms should be referred for surgery. ${ }^{19}$ Studies suggest that early surgical intervention for CSM can lead to improved neurologic outcomes. ${ }^{19-21}$ However, there is only one prospective randomized trial studying surgical versus nonsurgical management of cervical myelopathy. ${ }^{22}$ Bednarik and colleagues randomized 49 patients with CSM into surgical and nonsurgical management. Although patients with conservative treatment experienced improved clinical outcomes with respect to gait and modified Japanese Orthopaedic Association scores, there was no significant difference in outcomes at two years. Interestingly, this study excluded patients with severe CSM. As such, the results of this study may not be applicable to patients with advanced CSM.

\section{Surgical management of CSM}

The surgical management of CSM has evolved from the classic anterior cervical discectomy and fusion procedure developed by Smith, Robinson, and Cloward ${ }^{23,24}$ to now include combined anterior/posterior decompression and fusion procedures as well as a myriad of laminotomy techniques. It is critical to individualize a surgical plan for each patient based on the static mechanical factors that are contributing to a particular patient's CSM. Surgical techniques can be broadly divided into anterior surgery, posterior surgery, or combined anterior and posterior surgical techniques. The primary goal of all of these surgical techniques is to relieve compression of the spinal cord and its associated microcirculation. Other critical factors that must be considered are to maintain or restore alignment of the cervical spine and to ensure its long term mechanical stability. Surgeons must be keenly aware of the advantages, disadvantages, and limitations of each approach.

\section{Anterior surgical techniques for CSM}

Anterior surgical techniques for CSM are generally favored in situations where static mechanical pathology is primarily at the anterior aspect of the cervical canal. Anterior compression of the spinal cord secondary to disc/osteophyte complexes or ossified posterior longitudinal ligament are typical examples. Cord compression that is exacerbated by cervical kyphosis can also be addressed using anterior procedures that more readily restore normal cervical lordosis. Preoperative cervical traction using a halo device may be helpful in improving, if not restoring, normal cervical alignment before definitive surgical stabilization. 25

Anterior cervical decompression and fusion (ACDF) of 1-3 levels has been reported in multiple case series to be safe and effective in decompressing ventral pathology. ${ }^{26-} 30$ However, applying this procedure to greater than 3 levels can often result in complications, including 
graft extrusion, subsidence, fracture, and pseudoarthrosis. 26,27,30-32 ACDF is effective for ventral pathology that is confined to the cervical interspaces (i.e. osteophyte/disc complexes). Resection of the osteophyte/disc complex and placement of an interspace graft not only removes the offending ventral pathology but can also be used to restore lordosis to a straight or kyphotic spine.

Anterior cervical corpectomy is useful to address ventral pathology that extends beyond the cervical spine interspaces. Large osteophyte/disc complexes may extend posterior to the vertebral body. Such complexes may not be easily resected through a traditional ACDF approach. Compression from OPLL can also be addressed through a cervical corpectomy. Furthermore, irreducible kyphotic deformities (i.e. swan neck deformities) that exacerbate CSM are often best-addressed using cervical corpectomy.

Single-level corpectomy is generally considered safe and associated with successful outcomes for CSM. ${ }^{25,28,29}$ However, increasing the number of vertebral bodies resected during a corpectomy is associated with a significant increase in pseudoarthrosis rates. $26,28,33-35$ Vaccaro and colleagues studied the effect of the number of vertebral bodies resected on the rate of nonunion. Early instrumentation failure occurred in 9\% of patients with 2-level corpectomies with bone graft and ventral instrumentation. The failure rate increased to $50 \%$ in patients undergoing a 3-level corpectomy. ${ }^{28}$ Similarly, Sasso and colleagues reported a failure rate of $6 \%$ and $71 \%$ in patients with plated 2-level and 3-level corpectomies with iliac crest autograft, respectively. ${ }^{34}$ Daubs reported a much higher rate of failure in his series, with a $67 \%$ failure rate for patients undergoing 2-level corpectomies that increased to $100 \%$ for 3level corpectomies with titanium cage reconstruction and anterior plate placement. ${ }^{35}$

In summary, anterior cervical techniques are useful to address ventral pathology contributing to CSM. However, the literature clearly illustrates that increasing the number of levels included in ACDF or corpectomy procedures increases the risk of graft failure and other surgical complications. When utilizing multi-level ACDF or corpectomy procedures, surgeons should consider posterior instrumented supplementation to help limit these complications.

\section{Posterior surgical techniques for CSM}

Posterior surgical approaches to address CSM typically involve laminectomy with or without fusion or laminoplasty. These procedures allow for direct decompression of the cervical spine when the causative pathology is located at the posterior aspect of the spinal canal (i.e. hypertrophied ligamentum flavum). Posterior approaches also allow indirect decompression of the spinal cord from anterior pathology by enlarging the spinal canal and allowing the cord to migrate away from the offending pathology. Posterior approaches offer several advantages compared to anterior cervical approaches for CSM. For example, such procedures may not require fusion of vertebral levels, thus avoiding the cost and potential complications of instrumented fusion and limiting adjacent level spondylotic degeneration. In contrast to anterior approaches to the cervical spine, posterior approaches avoid exposure and injury to critical neck structures including the esophagus, recurrent laryngeal nerve, and carotid artery. Furthermore, direct visualization and decompression of nerve roots is possible using posterior approaches. Finally, posterior decompression procedures are particularly appealing in patients with congenitally narrow canals. The primary disadvantages of posterior approaches include the possibility of developing postlaminectomy kyphosis or instability. Furthermore, these approaches do not typically allow for primary resection of ventral canal pathology such as disc/ osteophyte complexes, particularly in association with pre-existing kyphotic deformity.

Patient selection is critical to ensure success and limit complications from posterior decompression procedures. Sagittal balance is a critical component in choosing the correct patient. Patients with cervical lordosis are ideal candidates for posterior decompression 
procedures, as the lordotic spine will allow the spinal cord to migrate posteriorly and away from ventral pathology. In patients with straightening of the cervical spine, the spinal cord may not be able to migrate posteriorly unless an instrumented fusion procedure is utilized to stabilize the spine after realignment in a lordotic fashion is achieved. Patients with cervical kyphosis are generally poor candidates for posterior decompression procedures, as the spinal cord is draped anteriorly over the vertebral bodies and will not migrate posteriorly. However, in some patients with reducible kyphotic deformities, adequate lordosis can occasionally be obtained using preoperative halo traction or intraoperative reduction maneuvers. These patients would require an instrumented fusion procedure after laminectomy in order to stabilize the spine in a lordotic position.

\section{Laminectomy}

Laminectomy has traditionally been the gold standard for posterior approaches for CSM (Figure 1). This technique has been well described in the literature and is considered a safe surgical procedure. However, the biggest complication after laminectomy is post-laminectomy instability/kyphosis. Patients in whom aggressive facet resection is undertaken, ${ }^{36}$ multiple lamina are resected, and where there is pre-existing instability are at increased risk of developing post laminectomy kyphosis. Studies suggest that the risk of postlaminectomy kyphosis in adult patients is between 6 and 52\% ${ }^{37-43}$ Resection of the $\mathrm{C} 2$ and/or C7 lamina or spinous processes may increase this risk. $37,39,44$

Patients at risk for developing post-laminectomy kyphosis may benefit from instrumented stabilization at the time of initial laminectomy. Instrumented fusion serves to both stabilize the cervical spine as well as secure the spine in an optimal lordotic configuration. There are multiple instrumentation techniques that have been well-described in the literature. The goal of instrumentation is to provide temporary structural stabilization to allow solid bone formation. Traditional techniques such as interfacet wiring have been replaced by modern lateral mass and pedicle screw fixation systems. These modern fixation systems depend on screws to anchor rods or plates along the lateral masses. In experienced hands, the placement of these screws is quite safe with very low risk of intraoperative iatrogenic injury.

Although there are several techniques for the placement of lateral mass screws, the most common techniques are the Magerl technique and the Roy-Camille technique. We favor the Magerl technique because it allows us to better avoid neurovascular structures. ${ }^{45}$ It also allows for longer facet screws to be placed, thereby allowing for greater load bearing before failure. ${ }^{45}$ However, a cadaveric study found no statistical difference in pullout strength between the two techniques. ${ }^{46}$ For fixation of $\mathrm{C} 2$, we prefer pedicle screws when the laminectomy includes this level. When the $\mathrm{C} 2$ lamina is intact, translaminar screws are preferred to avoid the risk of vertebral artery injury. When the construct stops at C7, pedicle screws are preferred at this level, as the C7 lateral masses are typically too small to support a lateral mass screw. With long constructs, we often extend the instrumentation across the mobile cervicothoracic junction to include $\mathrm{T} 1$ and $\mathrm{T} 2$ pedicle screws.

There are several complications inherent with instrumented fusion that should be considered, including the risk of neural injury, hardware failure, adjacent segment degeneration, and risk of vertebral artery injury. In a series of patients with posterior lateral mass instrumentation, Heller and colleagues found that the risk of nerve root injury was less than $1 \%$ per screw placed. ${ }^{47}$ No patients experienced injury to the vertebral artery or spinal cord. Their series reported a $3.8 \%$ incidence of symptomatic adjacent segment degeneration. 


\section{Laminoplasty}

Although laminectomy is widely regarded as the primary option to address CSM from a posterior approach, many surgeons utilize laminoplasty as a principle option. It has been well described in the Japanese literature for the treatment of OPLL, where anterior surgical procedures carry a high risk of complications including CSF leak. There are a variety of laminoplasty techniques described in the literature. Many of these techniques are derivations of the "open-door" laminoplasty technique. The "hinge" is created by drilling the outer cortex of the lamina unilaterally, thus preserving the inner cortex. On the contralateral side, the lamina and underlying ligamentum flavum is removed completely, thus creating the "open-door" side. The remaining lamina and spinous process is then swung towards the contralateral intact "hinge", thus enlargening the spinal canal. Autograft, allograft illiac crest, or bone spacers are then wedged between the lateral mass and remaining lamina of the "open-door" side and stabilized using titanium mini-plates.

It has been argued that laminoplasty offers several advantages over traditional laminectomy. By preserving the posterior elements (lamina, spinous processes), it has been suggested that laminoplasty may decrease the incidence of post-laminectomy kyphotic deformity compared to laminectomy alone. ${ }^{48}$ Compared to laminectomy with instrumented fusion, laminoplasty may have a decreased incidence of adjacent level spondylosis by preserving cervical range of motion. 49 However, the efficacy of laminoplasty over traditional laminectomy is unclear at present. A 2003 meta-analysis by Ratliff and Cooper suggests that there is no conclusive evidence that laminoplasty is superior to laminectomy.50 Their review of 71 series compromising more than 2000 patients showed that the mean neurologic recovery rate was $55 \%$. Interestingly, although the preservation of cervical range of motion is one hypothetical advantage of laminoplasty, the mean decrease in cervical range of motion was found to be $50 \%$. The incidence of postoperative axial neck pain was found to be between 6 and $60 \%$.

\section{Combined Anterior and Posterior Surgery for CSM}

Combined anterior and posterior approaches to the cervical spine may benefit certain patients with CSM (Figure 2). Some patients may have both anterior and posterior spinal canal pathology that cause compression of the spinal cord. For example, patients with compressive disc/osteophyte complexes in combination with hypertrophied ligamentum flavum may sometimes require both anterior and posterior surgery. Other patients who require anterior surgery may be at particular risk for graft failure and may benefit from posterior stabilization procedures. For example, patients who undergo multi-level discecotmy/corpectomy to address ventral pathology are at increased risk of graft failure and/or pseudoarthrosis. ${ }^{34}$ Patients with osteoporosis, medical renal disease, or smokers are also susceptible to pseudoarthrosis secondary to poor bone healing. The addition of posterior supplementation minimizes the risk of pseudoarthrosis in these high-risk patients. ${ }^{51-53}$ Supplemental posterior fixation has been shown to effectively add to the stability of the cervical spine in flexion and extension in biomechanical studies, thus translating into higher fusion rates. ${ }^{34,53-55}$ Patients who undergo revision surgery for CSM secondary to pseudoarthrosis, instability, hardware failure, or recurrent stenosis are particularly at risk for pseudoarthrosis or graft failure after revision surgery and may benefit from combined anterior-posterior surgery. In Gok and colleagues series of patients undergoing revision surgery for CSM, eleven patients underwent anteriorposterior revision surgery. Eight of eleven patients had improved neurologic function, and only one patient required revision surgery for pseudoarthrosis.

The disadvantages of adding posterior fusion to an anterior fusion is, of course, the cost and risk inherent to the second procedure. Although the addition of posterior fusion has been shown to contribute to longer hospital stays, this may be partially offset by performing the posterior fusion as part of a single-anesthesia procedure. Performing circumferential fusion in a single 
sitting may lead to decreased anesthesia time, decreased blood loss, and shorter duration of hospitalization. ${ }^{56}$ However, patients with significant comorbidities may benefit from a 2-stage procedure to allow for patient recovery and to avoid a prolonged single-stage surgery.

It is not unexpected that patients who undergo combined anterior-posterior surgery have an increased risk of complications. In a review of 67 patients with CSM secondary to anterior compression, patients undergoing combined anterior-posterior surgery had a higher risk of complications compared to patients undergoing anterior surgery alone (28.6\% vs. $24 \%){ }^{32}$ Interestingly, patients who underwent anterior surgery alone had a higher rate of adjacentsegment disease that led to revision surgery.

\section{Conclusion}

Cervical spondylotic myelopathy is a common disease that leads to significant clinical morbidity. Surgical intervention has been to shown to be an effective treatment option for many patients with CSM. Because it is currently difficult to accurately predict the clinical course of an individual patient with CSM, we believe that early surgical intervention for patients with even minor clinical signs of myelopathy is warranted to avoid more pronounced clinical manifestations of CSM. There are many surgical options for CSM, and each patient should have a surgical plan tailored to address each individual's unique clinical circumstance.

\section{Bibliography}

1. Baron EM, Young WF. Cervical spondylotic myelopathy: a brief review of its pathophysiology, clinical course, and diagnosis. Neurosurgery 2007;60:S35-S41. [PubMed: 17204884]

2. Brain WR, Northfield D, Wilkinson M. The neurological manifestations of cervical spondylosis. Brain 1952;75:187-225. [PubMed: 14934989]

3. Cusick JE. Pathophysiology and treatment of cervical spondylotic myelopathy. Clin Neurosurg 1991;37:661-681. [PubMed: 2009713]

4. Fehlings MG, Skaf G. A review of the pathophysiology of cervical spondylotic myelopathy with insights for potential novel mechanisms drawn from traumatic spinal cord injury. Spine 1998;20:27302737. [PubMed: 9879098]

5. Kumaresan S, Yoganandan N, Pintar FA, et al. Contribution of disc degeneration to osteophyte formation in the cervical spine: A biomechanical investigation. J Orthop Res 2001;19:977-984. [PubMed: 11562150]

6. Hoff JT, Wilson CB. The pathophysiology of cervical spondylotic radiculopathy and myelopathy. Clin Neurosurg 1977;24:474-87. [PubMed: 583693]

7. Hadley MN, Reddy SV. Smoking and the human vertebral column: A review of the impact of cigarette use on vertebral bone metabolism and spinal fusion. Neurosurgery 1997;41:116-124. [PubMed: 9218303]

8. Jumah KB, Nyame PK. Relationship between load carrying on the head and cervical spondylosis in Ghanaians. West Afr J Med 1994;13:181-182. [PubMed: 7841112]

9. Olive PM, Whitecloud TS 3rd, Bennett JT. Lower cervical spondylosis and myelopathy in adults with Down's syndrome. Spine 1988;13:781-784. [PubMed: 2973661]

10. Yoo K, Origitano TC. Familial cervical spondylosis: Case report. J Neurosurg 1998;89:139-141. [PubMed: 9647185]

11. Yue WM, Tan SB, Tan MH, et al. The Torg-Pavlov ratio in cervical spondylotic myelopathy: A comparative study between patients with cervical spondylotic myelopathy and a nonspondylotic, nonmyelopathic population. Spine 2001;26:1760-1764. [PubMed: 11493847]

12. Al-Mefty O, Harkey HL, Marawi I, et al. Experimental chronic compressive cervical myelopathy. J Neurosurg 1993;79:550-561. [PubMed: 8410225]

13. Lees F, Turner J. Natural history and prognosis of cervical spondylosis. Br Med J 1963;2:1607-1610. [PubMed: 14066179] 
14. Nurick $S$. The natural history and the results of surgical treatment of the spinal cord disorder associated with cervical spondylosis. Brain 1972;95:101-8. [PubMed: 5023079]

15. Clark CR. Cervical spondylotic myelopathy: History and physical and findings. Spine 1988;13:8479. [PubMed: 3194794]

16. Clarke E, Robinson PK. Cervical myelopathy. A complication of cervical spondylosis. Brain 1956;79:483-510. [PubMed: 13364095]

17. LaRocca H. Cervical spondylotic myelopathy: Natural history. Spine 1988;13:854-5. [PubMed: 3057650]

18. Fessler RG, Steck JC, Giovanini MA. Anterior cervical corpectomy for cervical spondylotic myelopathy. Neurosurgery 1998;43:257-267. [PubMed: 9696078]

19. McCormick WE, Steinmetz MP, Benzel EC. Cervical spondylotic myelopathy: Make the difficult diagnosis, then refer for surgery. Cleve Clin J Med 2003;70:899-904. [PubMed: 14621236]

20. Montgomery DM, Brower RS. Cervical spondylotic myelopathy: Clinical syndrome and natural history. Orthop Clin North Am 1992;23:487-493. [PubMed: 1620540]

21. Phillips DG. Surgical treatment of myelopathy with cervical spondylosis. J Neurol Neurosurgery Psychiatry 1973;36:879-884.

22. Bednarik J, Kadanka Z, Vohanka S, et al. The value of somatosensory and motor-evoked potentials in predicting and monitoring the effect of therapy in spondylotic cervical myelopathy. Prospective randomized study. Spine 1999;24:1593-1598. [PubMed: 10457580]

23. Cloward RB. The anterior approach for removal of ruptured cervical disks. J Neurosurg 1958;15:602617. [PubMed: 13599052]

24. Smith GW, Robinson RA. The treatment of certain cervical-spine disorders by anterior removal of intervertebral disc and fusion. J Bone Joint Surg Am 1958;40:607-624. [PubMed: 13539086]

25. Matz PG, Pritchard PR, Hadley MN. Anterior cervical approach for the treatment of cervical myelopathy. Neurosurgery 2007;60:64-70.

26. Papadopoulos EC, Huang RC, Girardi FP, et al. Three-level anterior cervical discectomy and fusion with plate fixation: radiographic and clinical results. Spine 2006;31:897-902. [PubMed: 16622378]

27. Stewart TJ, Schlenk RP, Benzel EC. Multiple level discectomy and fusion. Neurosurgery 2007;60:S143-S148. [PubMed: 17204876]

28. Vaccaro AR, Falatyn SP, Scuderi GJ, et al. Early failure of long segment anterior cervical plate fixation. J Spinal Disord 1998;11:410-415. [PubMed: 9811102]

29. Wang JC, Hart RA, Emergy SE, et al. Graft migration or displacement after multilevel corpectomy and strut grafting. Spine 2003;28:1016-1022. [PubMed: 12768141]

30. Wang JC, McDonough PW, Endow KK, et al. A comparison of fusion rates between single-level corpectomy and two-level discectomy and fusion. J Spinal Disord 2001;14:222-225. [PubMed: 11389372]

31. Bolesta MJ, Rechtine GR II, Chrin AM. Three and four-level anterior cervical discectomy and fusion with plate fixation: a prospective study. Spine 2000;25:2045-6.

32. Gok B, Sciubba DM, McLoughlin GS, et al. Surgical treatment of cervical spondylotic myelopathy with anterior compression: a review of 67 cases. J Neurosurg Spine 2008;9:152-157. [PubMed: 18764747]

33. Singh K, Vaccaro AR, Kim J, et al. Biomechanical comparison of cervical spine reconstructive techniques after a multilevel corpectomy oft the spine. Spine 2003;28:2352-2358. [PubMed: 14560082]

34. Sasso RC, Ruggiero RA Jr, Reilly TM, et al. Early reconstruction failures after multilevel cervical corpectomy. Spine 2003;28:140-142. [PubMed: 12544930]

35. Daubs MD. Early failures following cervical corpectomy reconstruction with titanium mesh cages and anterior plating. Spine 2005;30:1402-1406. [PubMed: 15959369]

36. Zdeblick TA, Zou D, Warden KE, et al. Cervical stability after foraminotomy: A biomechanical in vitro analysis. J Bone Joint Surg Am 1992;74:22-27. [PubMed: 1734010]

37. Chadduck WM. Cerebellar hemorrhage complicating cervical laminectomy. Neurosurgery 1981;9:185-189. [PubMed: 7266820] 
38. Herkowitz HN. A comparison of anterior cervical fusion, cervical laminectomy, and cervical laminoplasty for the surgical management of multiple level spondylotic radiculopathy. Spine 1988;13:774-780. [PubMed: 3194786]

39. Ishida Y, Suzuki K, Ohmori K, et al. Critical analysis of extensive cervical laminectomy. Neurosurgery 1989;24:215-222. [PubMed: 2918972]

40. Jenkins DH. Extensive cervical laminectomy: Long-term results. Br J Surg 1973;60:852-854. [PubMed: 4752728]

41. Mikawa Y, Shikata J, Yamamuro T. Spinal deformity and instability after multilevel cervical laminectomy. Spine 1987;12:6-11. [PubMed: 3576358]

42. Miyazaki K, Kirita Y. Extensive simultaneous multisegment laminectomy for myelopathy due to the ossification of the posterior longitudinal ligament in the cervical region. Spine 1986;11:531-542. [PubMed: 3097835]

43. Yonenobu K, Okada K, Fuji T, et al. Causes of neurologic deterioration following surgical treatment of cervical myelopathy. Spine 1986;11:818-823. [PubMed: 3810299]

44. Guigui P, Benoist M, Deburge A. Spinal deformity and instability after multilevel cervical laminectomy for spondylotic myelopathy. Spine 1998;23:440-447. [PubMed: 9516698]

45. Monetsano PX, Jauch E, Jonsson H. Anatomic and biomechanical study of posterior cervical spine plate arthrodesis: An evaluation of two different techniques for screw placement. J Spinal Disord 1992;5:301-305. [PubMed: 1520988]

46. Barrey C, Mertens P, Rumelhart C, et al. Biomechanical evaluation of cervical lateral mass fixation: A comparison of Roy-Camille and Magerl screw techniques. J Neurosurg 2004;100:268-276. [PubMed: 15029915]

47. Heller JG, Silcox DH, Sutterlin CE 3rd. Complications of posterior cervical plating. Spine 1995;20:2442-8. [PubMed: 8578396]

48. Kamioka Y, Yamamoto H, Tani T, et al. Postoperative instability of cervical OPLL and cervical radiculomyelopathy. Spine 1989;14:1177-1183. [PubMed: 2557677]

49. Shaffrey C, Wiggins GC, Piccirilli CB, et al. Modified open-door laminoplasty for treatment of neurological deficits in younger patients with congenital spinal stenosis: analysis of clinical and radiographic data. J Neurosurg Spine 1999;90:170-7.

50. Ratliff JK, Cooper PR. Cervical laminoplasty: a critical review. J Neurosurg 2003;98:230-238. [PubMed: 12691377]

51. Schultz KD Jr, McLaughlin MR, Haid RW Jr, et al. Single stage anterior posterior decompression and stabilization for complex cervical spine disorders. J Neurosurg 2000;93:214-221. [PubMed: 11012051]

52. Hee HT, Majd ME, Holt RT, et al. Complications of multilevel cervical corpectomies and reconstruction with titanium cages and anterior plating. J Spinal Disord Tech 2003;16:1-9. [PubMed: 12571477]

53. Kim PK, Alexander JT. Indications for circumferential surgery for cervical spondylotic myelopathy. Spine J 2006;6:299S-307S. [PubMed: 17097550]

54. Mummaneni PV, Haid RW, Rodts GE Jr. Combined ventral and dorsal surgery for myelopathy and myeloradiculopathy. Neurosurgery 2007;60:S82-S89. [PubMed: 17204891]

55. Nieto, JH.; Benzel, EC. Combined ventral-dorsal procedure. In: Benzel, EC., editor. Spine Surgery II: Techniques, Complication Avoidance, and Management. Vol. 1. Philadelphia: Elsevier; 2005. p. 402-406.

56. Spivak JM, Neuwirth MG, Giordano CP, et al. The perioperative course of combined anterior and posterior spinal fusion. Spine 1994;19:520-525. [PubMed: 8184344] 

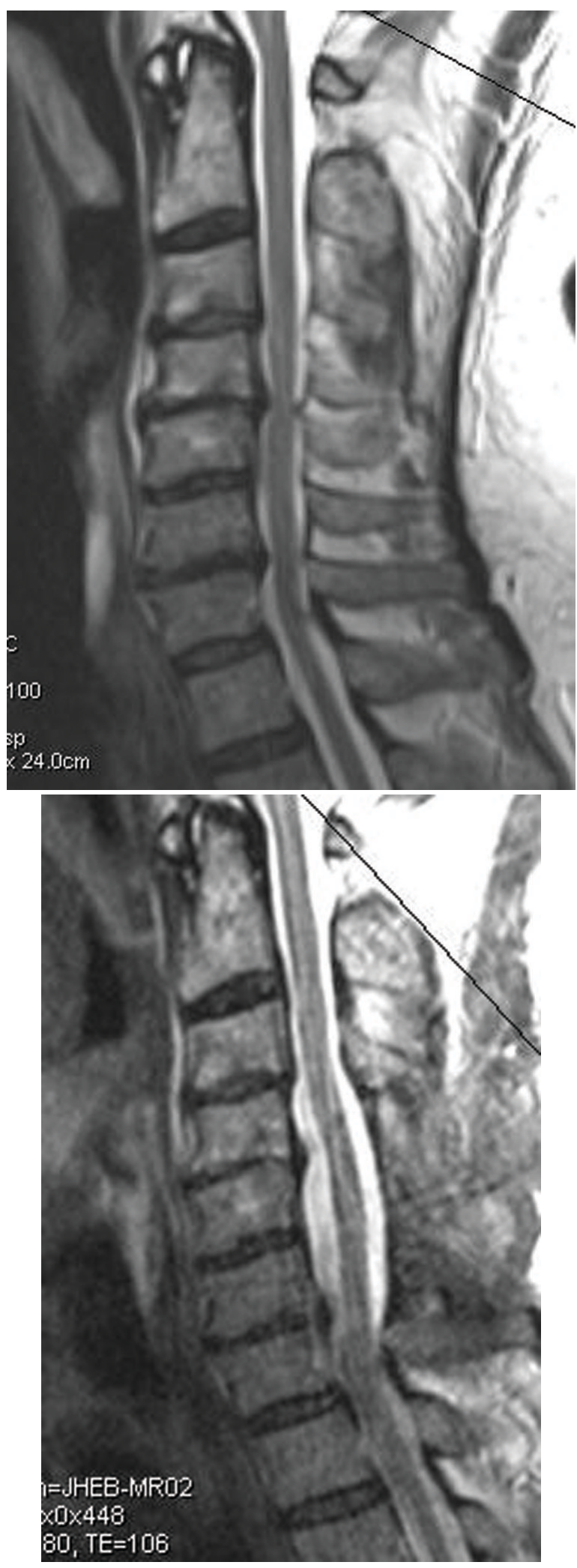

Figure 1. 
(a) Cervical MRI demonstrating multilevel cervical spondylosis most prominent at C4-5 and C6-7. This was addressed with a C4-6 laminectomy. (b) The postoperative MRI demonstrates enlargement of the spinal canal. 


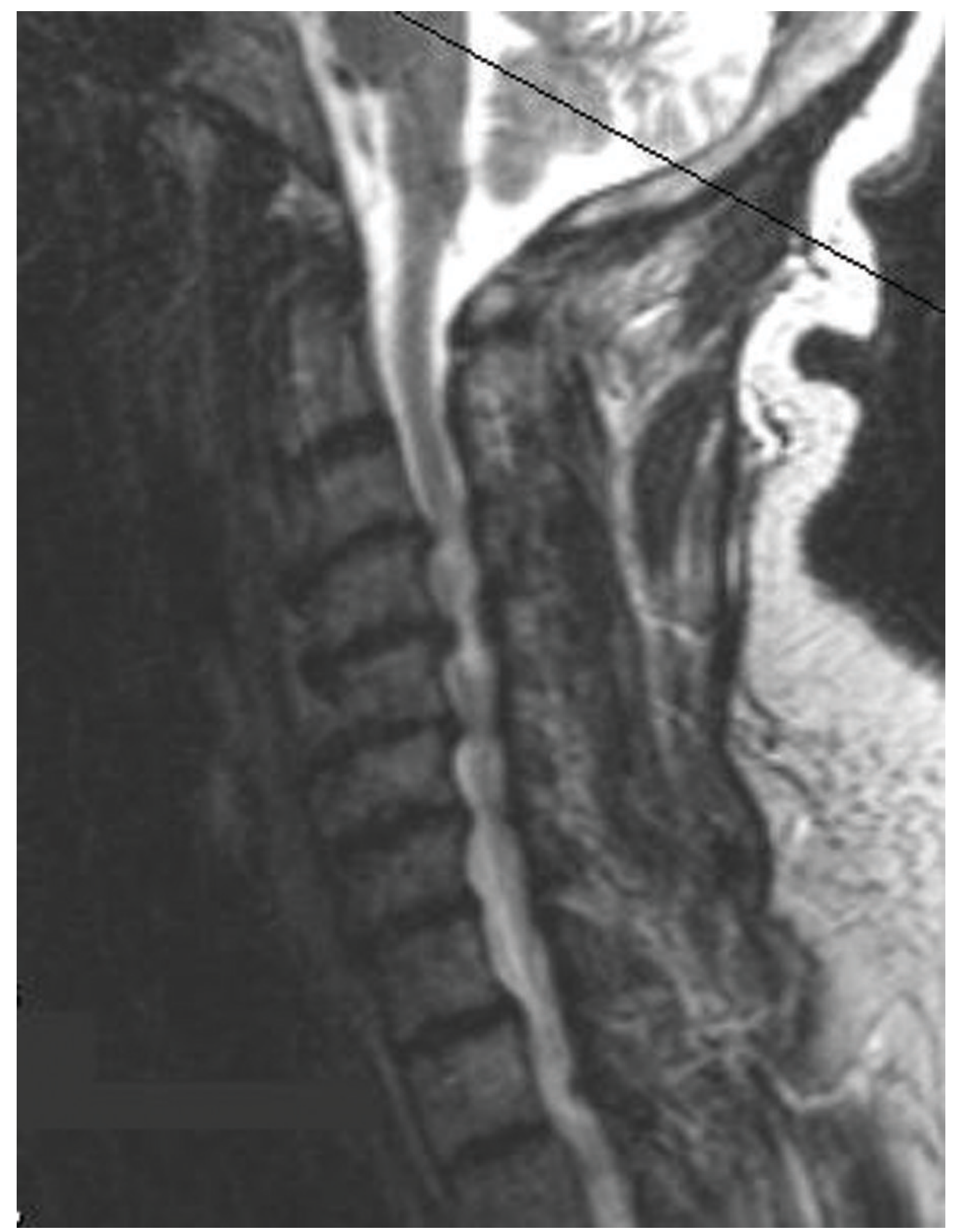




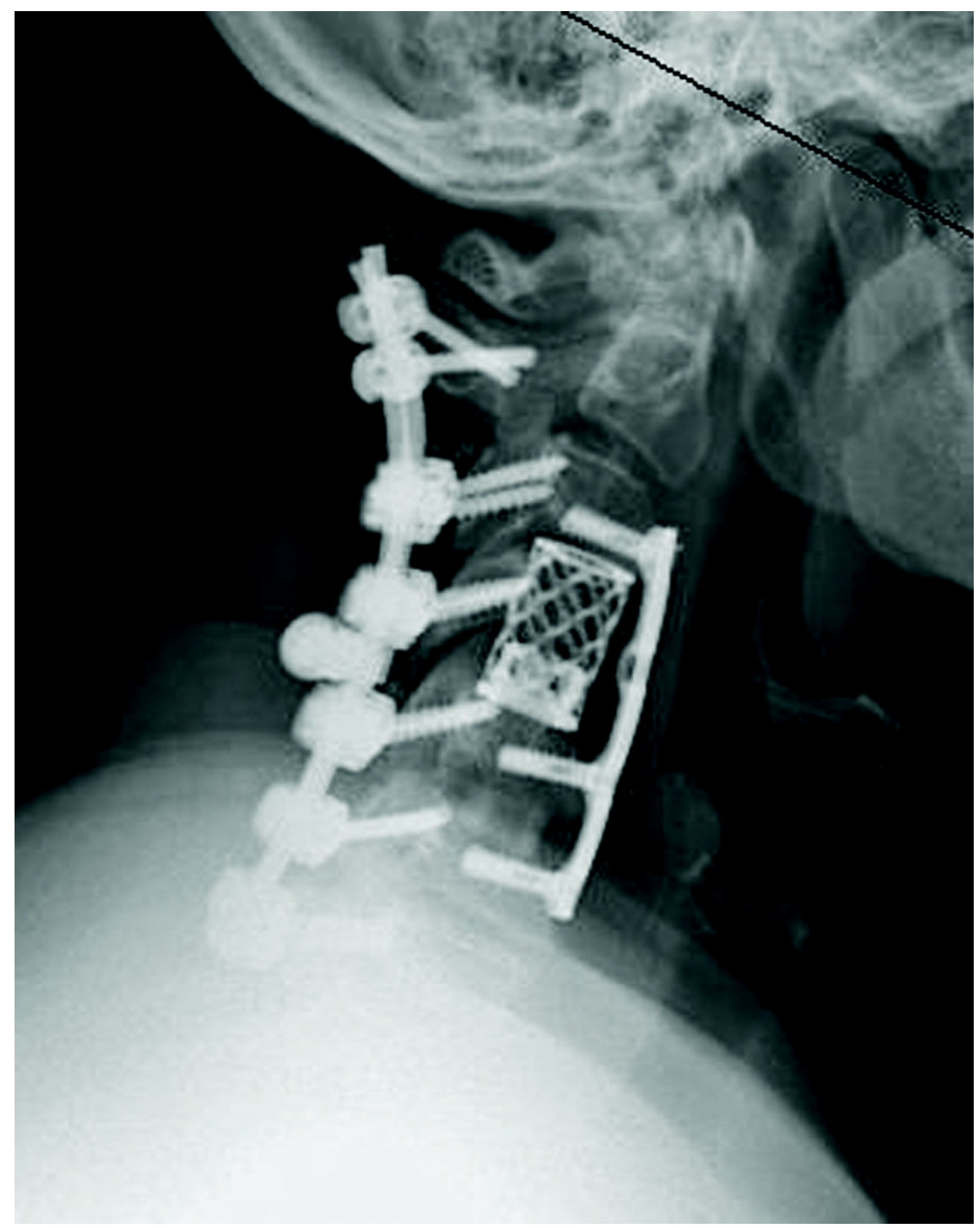

Figure 2.

(a) Cervical MRI demonstrating multilevel cervical spondylosis and cord signal change. (b) Postoperative CT scan after a staged anterior/posterior cervical decompression. 